\title{
Memorias de la sangre, memorias de la tierra. Pertenencia, identidad y memoria entre los indígenas del Noroeste Argentino, Atacama y Chile central durante el Período Colonial ${ }^{1}$
}

Viviana Manríquez S. ${ }^{2}$ y Sandra SáncheZ

\begin{abstract}
RESUMEN
Este artículo aborda el tema de los diversos usos y formas de la memoria indígena como sustentos de pertenencia e identidad a partir de algunos ejemplos de las poblaciones indígenas que habitaban tres espacios coloniales: Tilcara-Omaguaca en el Noroeste Argentino; Atacama en el norte de Chile y Chile central. Estos usos y formas de la memoria las hemos denominado "memorias de la sangre", "memorias de la tierra" y a través de ellas exploramos su importancia en la construcción de las identidades locales o "microscópicas", a través de distintas vías expresadas en la relación entre espacio, territorio e identidad; entre ésta y las relaciones sociales establecidas entre sus habitantes donde el parentesco juega un papel fundamental en su definición; en aquellas establecidas a través de los gentilicios o apelativos que cada grupo otorga a sus miembros; en la persistencia de una lengua propia, en la existencia de un sistema de medición del tiempo y de ritmos productivos propios así como también a través de la práctica de ciertos rituales o creencias. Finalmente, en los "senderos de la memoria colectiva" advertimos la construcción de contenidos y códigos que son elaborados y traspasados creativamente a los miembros del grupo otorgándoles sentido de pertenencia e identidad.
\end{abstract}

Palabras claves: memoria - identidad - poblaciones indígenas - Noroeste Argentino - Atacama - Chile central.

\section{ABSTRACT}

This papers takes on the theme by which diverse uses and forms of indigenous memory feed notions of belonging and identity, through the analysis of a few examples taken from indigenous populations in three colonial spaces: TilcaraOmaguaca in Noroeste Argentino; Atacama (in the North of Chile), and Chile central. We have called these uses

1 Este trabajo representa el quehacer interdisciplinario que comenzó hace algunos años en conjunto con Sandra Sánchez y que se vio truncado por la pérdida irreparable de nuestra colega y amiga. Lo relativo al Noroeste Argentino y parte de lo referido a Atacama era trabajado por Sandra Sánchez, y lo que se presenta en este artículo fue reconstruido a partir de notas preparatorias elaboradas por ella.

2 Universidad Academia de Humanismo Cristiano, Escuela de Antropología - Escuela de Historia, Condell 343, Providencia, Santiago, CHILE. Email: vmanriquez@academia.cl and forms of memory "memories of the blood" and "memories of the land". We explore their contribution to the construction of local or "microscopic" identities, as expressed in the fundamental role kin connections play in the relationships between space, territory and identity, as illustrated by the local terms of belonging by which each group designates its members, in the existence of a distinct language, time measuring systems based on their productive rhythms, as well as through the practice of characteristic rituals and beliefs. In these "paths of collective memory", we consider, finally, the construction of contents and codes that are creatively elaborated and passed over to the members of the group, along with a sense of belonging and identity.

Key words: memory - identities - indigenous peoples Noroeste Argentino - Atacama - Chile central.

Recibido: marzo 2004. Manuscrito revisado aceptado: julio 2004.

\section{Introducción}

Durante el Período Colonial los indígenas de distintas zonas de América despliegan una serie de mecanismos sociales y culturales basados fundamentalmente en los usos y formas de la memoria para construir espacios de pertenencia e identidad junto, y muchas veces entreverado, con el sistema colonial implantado por los españoles.

A este proceso lo hemos llamado "senderos de la memoria colectiva" y en él advertimos la elaboración, por parte de estas poblaciones, de contenidos y códigos que circulaban creativamente entre los miembros del grupo otorgándoles un sentido de pertenencia e identidad.

Trabajamos con memorias indígenas relacionadas al conocimiento de espacios, límites y lugares donde la memoria colectiva, en tanto construcción social y cultural, sitúa el lugar de los ancestros por medio de las "memorias de la sangre" y de las "memorias de la tierra" asociadas a una "sabiduría" sustentada en los lazos parentales establecidos entre los indígenas que habitaban o reconocían su origen en las distintas zonas analizadas. 


\section{"Memorias de la sangre"}

El parentesco, los gentilicios y los ancestros

A través de las "memorias de la sangre" es posible advertir el despliegue de una lógica indígena para organizar sus relaciones sociales y políticas que funciona entre, bajo o a la par de la lógica hispana y que involucra, además de la adscripción a un territorio y un espacio de origen, los vínculos familiares que contienen una "sabiduría lentamente acumulada y casi innata, de la sangre" (Fox 1972: 16). A esta "sabiduría" los indígenas recurren constantemente, porque constituía para ellos la base de las relaciones sociales, políticas, económicas y rituales.

La importancia del gentilicio en la memoria colectiva y la identidad de los indígenas de Chile central se expresa en lo planteado por el jesuita Miguel de Olivares, en relación al problema que constantemente tienen los padres misioneros al intentar bautizar con nombres cristianos a los naturales quienes:

"tuvieron dificultad i la tienen grande cuando los padres les empezaron a predicar en dejar el nombre que tenian, i llamarse como nombre cristiano, porque los otros les hacian burla por haber dejado el nombre de sus mayores... así ellos quieren ser nombrados por los apellidos de sus linajes, que unos son de leones Pargue, tigres Naguel, culebras Vilu, águilas Nunca, flecha Pelgui, lanza Huaique, etc. aunque se les decia que podian tener uno i otro, no se querian reducir" (Olivares [s. XVIII] 1864: p. 89). ${ }^{3}$

En el colonial "pueblo de indios de Rapel" (Figura 1), desde el siglo XVII están presentes los Millategua, Malgue y Rapilauquen, quienes poseen un conocimiento de sus relaciones parentales, sociales y políticas "desde tiempo inmemorial", el cual mantienen de manera dinámica, por medio de constantes adecuaciones y definiciones (Manríquez 1997).

Lo anterior nos indicaría la existencia de una "solidez dúctil" de los lazos parentales existentes entre ellos, así como también nos estaría hablando de la capacidad de estas poblaciones para or-

El destacado es nuestro. denar, adecuar y poner en escena nuevas estrategias de funcionamiento frente a una manera distinta de ejercicio del poder, que genera la presencia hispana en la zona. Un ejemplo de la vitalidad de los lazos parentales o "memoria de la sangre" entre los indígenas que habitaban esta zona lo constituye el hecho de que recuerdan su ascendencia y relaciones parentales, además de los lugares de origen de sus progenitores, y transmiten esta "sabiduría de la sangre" a sus descendientes por generaciones. Esto lo advertimos claramente cuando se entablan juicios, por el derecho a ejercer el cacicazgo, por ejemplo, entre dos linajes.

Quizás una de las más bellas descripciones sobre la "memoria de la sangre" y "la memoria de la tierra" se expresa en una petición de los caciques e indios del "pueblo de Mataquito" (Figura 2), realizada en 1602, para que un indio perteneciente al pueblo sea devuelto, señalando que:

"Pedro Toman yndio que al presente esta ausente de su pueblo y en el de la ciudad de Santiago es hijo de Pedro Mana yndio natural del dicho pueblo y ermano del cazique Guequilaquy [?] sobrino de el dicho Pedro Toman el qual dicho Pedro Mana se huyo de las minas y se fue a la ciudad de la Concepcion y alli fue casado con una yndia natural de Puchacay y ubo por hijo al dicho Pedro Toman el qual siendo ya muchacho de hedad y capaz para entender quienes heran sus parientes y su tierra y como hera su hermano el cazique prinçipal de su Mataquito y que aquella hera su tierra por la relaçion que le dio su padre se bino a ella y ansi como llego se recoxio y bibio con Elena yndia su abuela adonde estubo seys años y despues se fue tras de una yndia que llebaua su ama a Santiago por que se pretendio casar con ella y ansi se caso la qual es natural ansi mismo del dicho pueblo de Mataquito y sirbio a su encomendero en Santiago otros seis o siete años y al presente esta ausente de su seruycio [...] pido y suplico en nombre de los caziques e yndios ... que el dicho Pedro Toman sea buelto y restituido al dicho su pueblo". 4

La situación anterior se ve constantemente referida en los documentos de la época donde la "sabi-

\footnotetext{
4 "Visita al obraje de Peteroa del capitán Juan Jufré, realizada por el visitador general capitán Gregorio Sánchez, 16021609", Archivo Nacional Fondo Real Audiencia volumen 1700, foja 117r. El destacado es nuestro.
} 


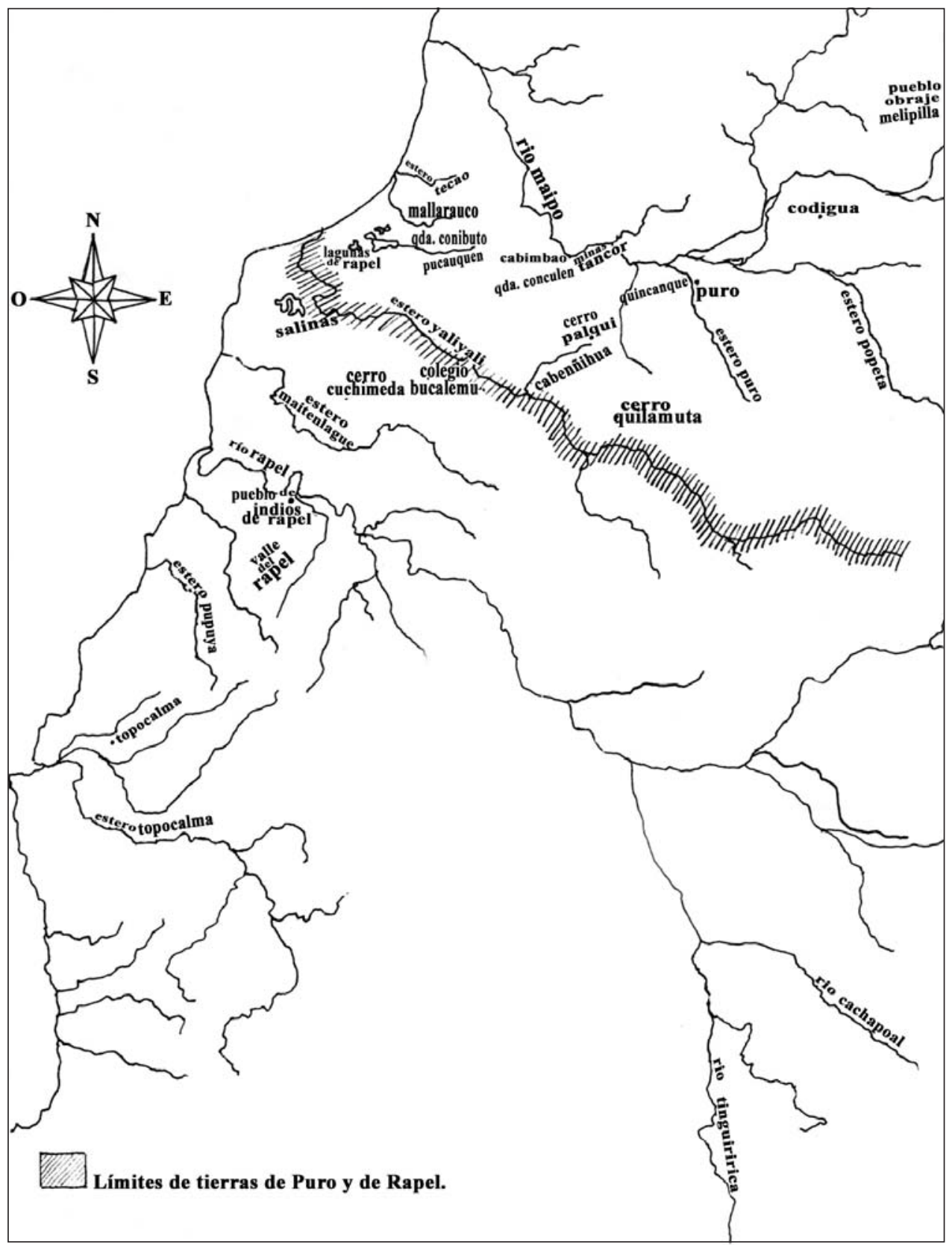

Figura 1. Tierras de Puro y Rapel (siglos XVI y XVII). Fuente: Archivo Santo Domingo. Censos y capellanías, causa Rapel, vols. 11 y 12.

duría de la sangre" se impone al desmembramiento y traslado de individuos, unidades domésticas, linajes o familias extensas que los españoles llevan a cabo a través del sistema de trabajo basado en la encomienda o por la acción de los españoles que participan en las "guerras de pacificación", que los "hurtan" y los llevan consigo como indios de servicio. Aquí pierde importancia el lugar donde determinado indígena o grupo de indígenas esté asentado en un momento histórico concreto, ya que se perpetúa la identidad relacionada a la memoria de pertenecer a un territorio específico, donde el conocimiento de las redes de parentesco y del lugar de origen de sus antepasados son fundamentales. 


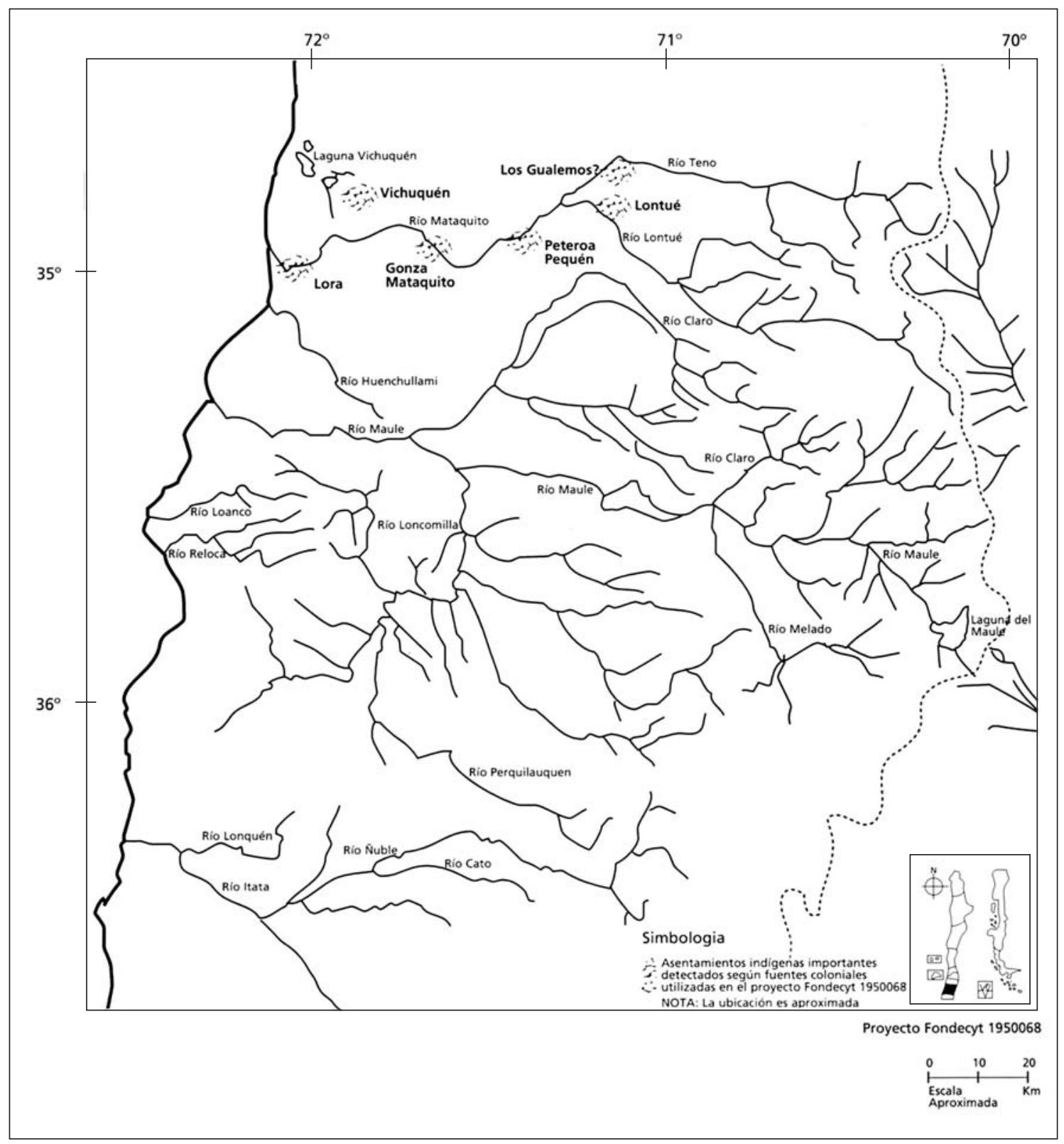

Figura 2. Valle del río Mataquito (siglos XVI-XVIII).

Pensamos que esta situación se produjo en el siglo XVI, durante la rebelión indígena, liderada por Lautaro, quien intenta concitar la adhesión a la sublevación de los indígenas de la zona del Maule diciéndoles:

"una oración con palabras recias y bravas...; y pues vían cuán oprimidos estaban, tomasen las armas y se juntasen todos... que echarían a los cristianos de toda su tierra, pues ellos eran hom- bres y tenían tan grandes cuerpos como otros indios cualesquiera. Con sus pies y manos libres, ¿en qué les podían hacer ventaja, pues todos eran unos y parientes antiguos? ... que les rogaba las tomasen y enviasen mensajeros los unos a los otros para que todos con su voluntad tomasen aquella guerra" (Góngora Marmolejo 1990: 143). ${ }^{5}$

5 El destacado es nuestro. 
La memoria de la lengua materna

Queremos destacar el hecho de que los indígenas, en la mayoría de los casos, mantuvieron el conocimiento y la práctica cotidiana de su lengua a pesar de las fuertes presiones ejercidas por los españoles, lo que hizo posible el desarrollo y la capacidad de construir y elaborar una historia propia, perpetuando la memoria de los antiguos a través de la mantención de algunos contenidos que estas poblaciones indígenas consideraban centrales para su identidad. A la par, permitió la creación de nuevos contenidos que se "desplegaban" en situaciones históricas concretas. El hablar en la lengua propia permitió poseer una memoria colectiva, que se expresó en la oralidad o la escritura, que se conservó y expresó en el ejercicio de la vida cotidiana (Abercrombie 1998). En los tres ámbitos trabajados, la mayoría de los testigos indígenas requerían de un intérprete para declarar, e incluso aquellos indígenas que eran indicados como "lenguaraces" o "ladinos" en la lengua castellana poseían un conocimiento de ciertas pautas culturales "claves" para el soporte de la identidad, las que expresaban en la lengua "materna".

En Atacama colonial la lengua propia se utilizaba "entre pares" en contextos donde era necesario comunicarse y negociar con los españoles acerca de aspectos políticamente trascendentes para ambas partes como sucedió en el proceso de "pacificación de Atacama" del siglo XVI. En 1557, en el pueblo "Atacama la Grande", don Andrés de Chuchilamasa "traduce" a "don Juan caçique prençipal y los demas sus caçiques e prençipales e yndios a el subjetos" y

"aviendo visto y entendido el diçho perdon e cartas en su lengua respondio el diçho caçique prençipal al diçho don Andres ynterpetre [sic] que queria comunicar lo susodicho con los diçhos sus caçiques y prençipales y que responderia el qual luego se aparto por si con ellos a hablar y tratar sobre lo que se les avia propuesto". ${ }^{6}$

La lengua propia también en estos contextos facilitó la interacción social con otros "indios". En 1557, don Andrés de Chuchilamasa, "gobernador

6 Archivo General de Indias (A.G.I.) Patronato Legajo 188 $\mathrm{N}^{\circ}$ 1, año 1557, foja 2v (en Martínez 1992). El destacado es nuestro. y cacique de la provinçia de los yndios chichas", no solo ejerció de intérprete entre los caciques y "principales" de la Provincia de Atacama, ${ }^{7}$ negociando además -con ellos- el someterse a la Corona española y a la Iglesia. Su bilingüismo le permitió ejercer una función política de "bisagra" entre hispanos y "atacamas", quizás rearticulando una práctica prehispana.

Sin embargo, desde inicios del Período Colonial hay fuertes presiones, por parte de las autoridades eclesiásticas y administrativas hispanas, para erradicar la lengua "materna"; proceso que se va a profundizar aun más desde fines del siglo XVII y especialmente durante el siglo XVIII, donde el manejo del español -por parte de los indígenases cada vez mayor. ${ }^{8}$ En estas situaciones el hablar en español también se transformó en una nueva vía de expresión de ciertos contenidos esenciales para la cultura de los "atacama", ya que el español será cada vez y con mayor fuerza también el sendero de expresión de identidad (Abercrombie 1998). Por otra parte, las mujeres en el mismo período hablaban preferentemente la lengua "materna", situación que se constata aun en el siglo XVIII. En 1749, en el pueblo de San Pedro de Atacama se inscribió en el "quaderno sobre barios delitos y superticiones" la declaración de dos indias "originarias" de este pueblo acusadas de "brujería", y al momento de declarar es "necesario nombrar interprete para tomar sus declaraciones", designándose al gobernador "don Francisco Siari" quien, "abiendo hablado con ella en su lengua me respondió" (Castro e Hidalgo 2001 [1999]). ${ }^{9}$ Quizás las mujeres, principalmente, eran quienes mantenían ciertos signos de pertenencia a través del conocimiento de su lengua y eran quienes los trasmitían a sus hijos en la crianza cotidiana.

Todos estos elementos se ven penetrados por la existencia de una memoria colectiva, transmitida a través de la oralidad, o a través de la apropiación de la escritura, la que traspasa conocimientos acumulados, reconstruidos o aprendidos. La memoria colectiva propia, a un nivel más local y quizás también a un nivel regional, constituye un

7 Archivo General de Indias (A.G.I.) Patronato Legajo 188 $\mathrm{N}^{\circ}$ 1, año 1557, foja 1r (en Martínez 1992).

8 Este tema ha sido profundamente trabajado para la zona de estudio por Jorge Hidalgo (1984).

9 El destacado es nuestro. 
elemento fundamental en la expresión, la elaboración y mantención de las identidades.

En Chile central el mapudungun y su práctica cotidiana encerraba la posibilidad de elaborar una historia propia y perpetuar en ellos la memoria de los "antiguos", además de permitir la existencia de ciertos contenidos que, para los indígenas, eran parte fundamental en la elaboración y expresión constante de su identidad local.

Múltiples referencias sobre los indios de Humaguaca y Tilcara, para fines del siglo XVII y principios del XVIII, nos indican que éstos declaraban en su lengua a través de intérpretes y muchas veces no sabían hablar español, hablando lengua quechua, general o lengua omaguaca. Es el caso para 1580 en un juicio contra don Andrés Tolay, cacique del pueblo de Omaguaca, donde se señala que a la madre de un declarante se la ha escuchado hablar siempre en "lengua omaguaca" (Sandra Sánchez, com. pers. 2003). ${ }^{10}$

"Borracheras" y juegos de chueca

Pensamos que entre las poblaciones indígenas del período estudiado ciertas prácticas rituales también eran expresiones de la memoria colectiva de los indígenas y sostenían el funcionamiento de las identidades locales formando parte a la vez de códigos compartidos a nivel más general, destinados a revitalizar las pertenencias e identidades.

En el caso de Chile central lo anterior se expresa en las "borracheras" como un beber social y comunitario y en la realización de juegos de chueca, que se constituyeron en espacios simbólicos y materiales de recuerdo y conexión con los ancestros. ${ }^{11}$

Así lo expresó el cronista Diego de Rosales señalando que:

"los caciques son las cabezas de las familias y linajes [...] y assi el modo conveniente de ordenar alguna cosa conveniente para la paz y para la guerra es juntando en su casa a los de su

10 Esta cita aparece en los apuntes de Sandra Sánchez como Legajo 564, foja 9r, pero no se indica el archivo ni el fondo de origen.

11 Para este tema ver los sugerentes trabajos compilados en Saignes (1993). parentela y convidandolos a beber chicha y a comer" (Rosales 1989: 136). ${ }^{12}$

El juego de la chueca era un ámbito donde se reafirmaban los lazos y las relaciones entre individuos y grupos de indígenas, entendiéndose también como una "guerra ritual" mediante la cual se establecían jerarquías entre quienes participaban del juego y donde, además, se podían vitalizar y reafirmar identidades.

Es el caso de Rodrigo Cuchimeda y sus hijos indios encomendados. Este indígena era originario de Teno ${ }^{13}$ y fue trasladado al sector de Bucalemu por su encomendero. El y sus parientes participaban constantemente en juegos de chueca que se realizaban en la estancia de los padres de Santo Domingo, vecina a la de Bucalemu. ${ }^{14}$ Además, Cuchimeda junto a otros indígenas, en la quebrada de Cabenguiña "casi todos los días bebían". ${ }^{15}$

También lo observamos en la declaración de Luis Cuy, indio de la encomienda del maestro de campo general Juan Rodolfo Lisperguer, originario del pueblo de Putagán y residente en 1701 en la estancia de la Candelaria, situada en el partido de Colchagua, quien indicaba que "Pablo Guenulebi [Carilonco] sus hijos y desendientes (del pueblo de Cauquenes) ... iban algunas veses a ella [a la estancia de la Candelaria] a beber y a jugar la chueca". ${ }^{16}$

Las "borracheras" y juegos de chueca se constituyen en un lugar de memoria y en un espacio ritual comunitario que también remite a una revitalización constante de los lazos de cooperación, que los participantes van tejiendo finamente a través de la interacción.

A su vez, el juego de la chueca podía ser el vehículo de integración de un indio, considerado como "forastero", a un determinado linaje ya que el jue-

12 El destacado es nuestro.

13 Localidad situada en la actual VII Región, Chile (Figura 1).

14 Censos y capellanías, causa Rapel, 1630. Archivo Santo Domingo, volumen 11, foja $123 \mathrm{r}$.

15 Censos y capellanías, causa Rapel, 1630. ASD, volumen 11, f. $130 \mathrm{r}$.

16 “... Autos fechos sobre la vacante de la encomienda de yndios del pueblo de Cauquenes... [1679]" en Archivo Nacional Fondo Real Audiencia, volumen 2750 pieza 2, foja 170v. El destacado es nuestro. 
go sirvió para establecer su pertenencia a una identidad local, basada en el acto de darle el nombre del linaje durante el juego. De hecho, en el pueblo de indios de Guenchullami, el indio llamado Gabriel Lingo o Gabriel Mariqueupo que declaraba ser forastero de "nación cuzco", y haber obtenido el derecho al cacicazgo del mencionado pueblo a través del matrimonio con la hija del cacique legítimo don Sebastián Guiquibilo, cuando éste muere; sin embargo, fue a través del juego de chueca donde se le dio el "nombre" Lingo, apelativo de uno de los linajes más importantes de ese lugar. Su hijo declara lo siguiente:

"respondió este dicho declarante que aviendole preguntado a su padre que por que le llamaban Lingo le respondio y dixo que aviendo ydo su padre a un juego de chueca con el dicho don Francisco Lingo y aviendo ydo conbidado le dixo el dicho don Francisco Lingo al dicho forastero dentra al juego y le [cortado: dijo] el forastero como e de dentrar si en mi tierra çe mientan al juar y le respondio dentre y ponete mi nombre y mentate Quilalingo y aviendo dentrado al juego çe nombro Quilalingo y por eso le llaman Lingo". ${ }^{17}$

Las otras cuentas, los otros tiempos, los quipus

Como otras formas y usos de la memoria colectiva están las elaboraciones indígenas del tiempo, del espacio y de sus medidas, que no guardan relación con aquellas impuestas por los españoles.

Así lo percibe el cronista jesuita Miguel de Olivares, quien informaba que los indígenas del "reino de Chile" tenían un cómputo propio del tiempo señalando que:

"es cosa mui de notar que no pudiendo hacer sus cálculos ni por número de los dias del mes, ni por nombres de los dias de la semana que no saben de eso, sino que se convocan para los tantos dias de la luna proxima venidera o de la siguiente" (Olivares [s. XVIII] 1874: 57). ${ }^{18}$

\footnotetext{
17 "Litigio por el cacicazgo del pueblo de indios de Guenchullami", s/f, siglo XVIII" en Archivo Nacional Fondo Real Audiencia volumen 1160 pieza 3, foja 197v. El destacado es nuestro. Agradezco a Carolina Odone quien me facilitó esta referencia.

18 El destacado es nuestro.
}

Entre los indios del "pueblo de Rapel", hasta al menos el primer tercio del siglo XVII, son constantes las alusiones a las cuentas del tiempo y a las medidas propias; un testigo indígena señalaba que no sabía a cuántas leguas corresponde una distancia, porque "los yndios cuentan las leguas diferentemente que los españoles". ${ }^{19}$

En relación a los quipus, durante el siglo XVIII se constata su existencia en diversas localidades del sector de Santa María, en el Noroeste Argentino; los quipus están siendo utilizados y posiblemente elaborados entre las élites indígenas que ejercían los cargos de caciques. Los quipus fueron utilizados fundamentalmente como una forma de memoria administrativa, pero que también puede haber contenido nociones de una memoria histórica entre estos indígenas (Sandra Sánchez, com. pers. 2003).

En 1618, Martín Cheuquear, cacique de Peteroa, declara en "su lengua" que "açiste de ordinario en Peteroa con los yndios que ay alli a el benefiçio de las haçiendas" y que él junto a los pastores contó el ganado ovino e "hizo los quipos". ${ }^{20} \mathrm{In}$ dependiente del nombre que se le dé a esta manera de cuantificar y categorizar ciertos atributos del ganado, lo importante aquí es que entre los indígenas estaba operando un sistema propio para construir y expresar su memoria, el que era utilizado de manera constante y cotidiana, y trasmitido de generación en generación, reafirmado en el hecho de que este cacique lo expresaba "en su lengua".

\section{"Memorias de la tierra": Memoria, espacios e identidad}

En relación a las "memorias de la tierra", observamos cómo los indígenas construyen y despliegan una memoria acerca de los espacios y territorios de los antiguos que "teje, a la vez, una memoria íntima y una memoria compartida entre

19 Censos y capellanías, causa Rapel, 1630. Archivo Santo Domingo, volumen 11, foja 141r cit. en Manríquez 1997. El destacado es nuestro.

20 "Haciendas de Peteroa y Villavicencio de los herederos del general Luis Jufré. Causa entre Martín de Briones y Pedro Fonseca sobre cuentas de la administración de las haciendas de Luis Jufré en Peteroa y sus términos", 1618. Archivo Nacional, Fondo Real Audiencia, volumen 1065 pieza 1, foja 242v. El destacado es nuestro. 
próximos" que se transforma gradualmente en memoria colectiva (Ricoeur 2003: 194).

Pensamos que el hecho de conocer y manejar el espacio que se habita o se utiliza para desplegar la vida remite a la existencia y constante creación de una memoria colectiva que se transmite a través de la oralidad y de la apropiación de la escritura impuesta por los hispanos, los conocimientos acumulados, reconstruidos o aprendidos, y apunta a una voluntad de conservar "una memoria más creadora que repetitiva" (Le Goff 1991: 135 y 138) que se acumula en el ejercicio de la vida cotidiana. ${ }^{21}$

Son reiteradas las declaraciones de los testigos indios, "naturales" de determinados espacios, que tenían un conocimiento transmitido de generación en generación y en su lengua de la toponimia, los hitos geográficos e incluso de los límites que ellos consideraban como sus territorios "ancestrales".

En el caso de los indígenas que habitaban la colonial Atacama la Grande o la Alta, existió una compleja y profunda relación entre memoria, identidad y construcción del espacio. La administración hispana "fijó" a la población a los ayllus de Sequitur, Soncor, Solcor, Coio y Veter, Conde Duque, Cantal y Acapana, Toconao, Socaire, Peine y Cama, mencionando al Pueblo de San Pedro de Atacama la Alta emplazado en la zona del ayllu Conde Duque (Figura 3). ${ }^{22}$ Estos ayllus incluían distintos espacios productivos que abarcaban diversos oasis, quebradas y valles que adscribían a los indígenas a un espacio de origen donde estaban sus ancestros.

Así lo señala Vivar en el siglo XVI cuando describe el "pueblo o valle de Atacama" y refiere las "costumbres de yndios" observando que en:

21 Nos parece sugestivo lo que señala Le Goff en relación a los polos de interés en torno a los cuales se organiza la memoria colectiva en las sociedades ágrafas: "la identidad colectiva del grupo, que se funda sobre ciertos mitos y, más precisamente, sobre ciertos mitos de origen; el prestigio de la familia dominante, que se expresa en genealogías; el saber técnico, que se transmite a través de fórmulas prácticas fuertemente impregnadas de magia religiosa" (1991: 138).

22 Padrón y Revisita de Atacama del Corregidor Alonso de Espejo, ordenada por el virrey Duque de La Palata. AGNA, sala IX 7:7:1, 52 fs. (Año 1683). Transcripción de Jorge Hidalgo L., Nancy Hume, María Marsilli y Rebeca Correa (1992). "un apartado de las casas, cerca de donde duermen qu' es el más prinçipal, está hecho de bobeda alta fasta el entresuelo y cuadrada. Aqueste es su enterramiento y sepulcro. $Y$ allí dentro tienen a sus bisaguelos y aguelos y padres y toda su generaçion" (Vivar [1558] 1979: 20). ${ }^{23}$

En este espacio se establecía un nexo entre parentesco, identidad y territorio de origen definido por el lugar donde descansaban los ancestros.

Gran parte de los miembros de los ayllus de Atacama conocía los nombres y lugares asociados al ayllu, así como muchas veces comprendía la potencia simbólica de su significado; junto a esto conocía los "límites" de los ayllus, los que incluían parajes, vegas, quebradas, valles, cursos de agua y lugares rituales. Aquí creemos percibir mecanismos de construcción de identidad, a partir de la constante actualización de la memoria colectiva en la vida cotidiana, asociada a la pertenencia a un ayllu y a la utilización (productiva y ritual), de un espacio y territorio que es considerado por los indígenas como propio, así como también la existencia de topónimos de importancia relacionados con elementos de la naturaleza que tienen un fuerte contenido simbólico y ritual.

Ejemplo de lo expuesto se daba con Socomba, que denominaba a un cerro ritual y simbólicamente trascendente para los habitantes de Atacama siendo además mencionado en el siglo XVII como el nombre de uno de los "ídolos" de Ayquina ${ }^{24}$ y finalmente señalado como el nombre del curaca de Omaguaca en este mismo periodo, ${ }^{25}$ a través de este nombre se inscribe en la memoria colectiva de los indígenas la relación entre la noción de deidad, autoridad y un hito natural (cerro-mallku) que simbolizan en distintos planos lo masculino.

En el Noroeste Argentino (NOA), en la quebrada de Humahuaca (Figura 4) veremos la relación entre memoria, territorio e identidad a partir del curaca Viltipoco, del pueblo de Tilcara y los tilcara.

Hacia fines del siglo XVII en el Noroeste Argentino, don Diego Viltipoco, una vez apresado y en-

23 El destacado es nuestro.

24 AGI, Charcas 92, foja 40v; Martínez 1998; Castro 1997; Sánchez 2001 Ms., citados en Manríquez 2002 Ms.

25 Sandra Sánchez, apuntes marzo 2003. 


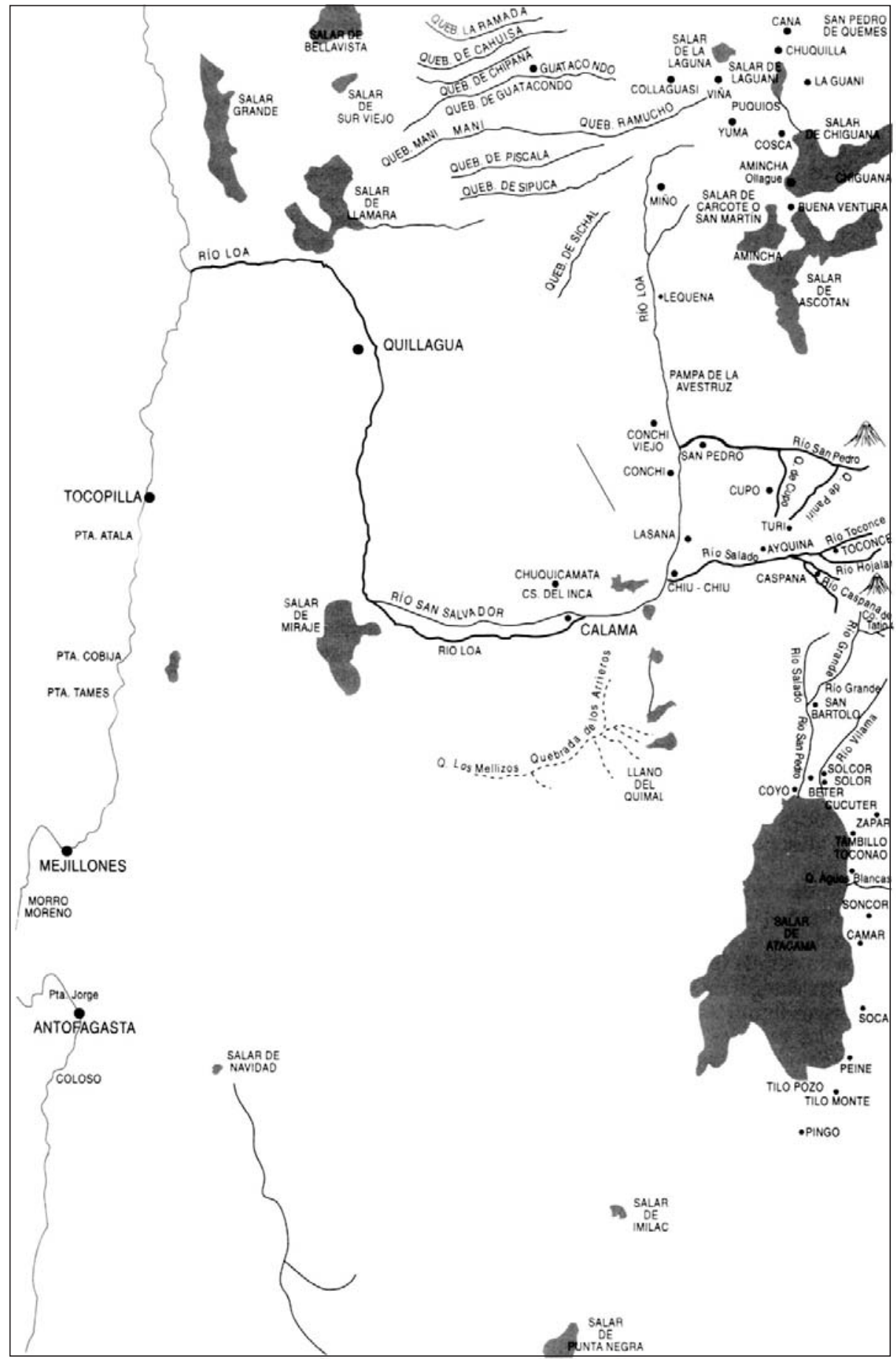

Figura 3. Poblados indígenas en la cuenca del río Loa y cuenca de Atacama. Tomado de Castro y Martínez (1996: 72).

carcelado, es interrogado acerca de su rol político en el valle de Omaguaca; lo mismo sucede con los demás curacas hechos prisioneros junto con él. En este nuevo contexto, la figura del jefe gue- rrero de la "provincia de Omaguaca" se hace a un costado, y da paso al personaje político, al señor de indios y pueblos de la quebrada y de su flanco oriental. En este sentido, el pueblo de Puruamarca 


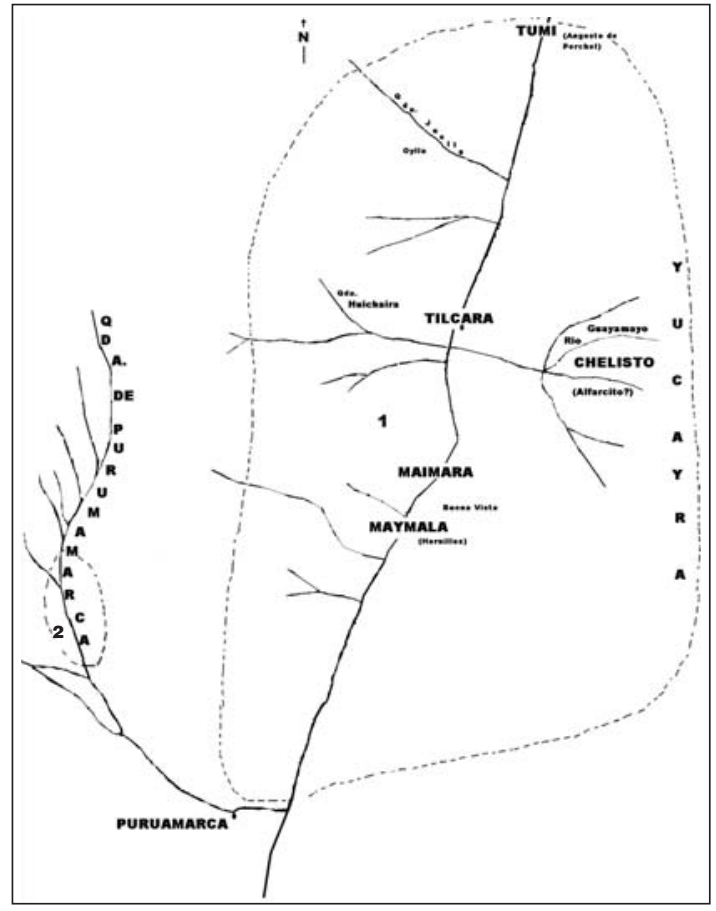

Figura 4. Tierras de la comunidad y pueblo de San Francisco de Tilcara (siglos XVI-XIX). Mapa realizado por Sandra Sánchez en base a Documentos de los siglos XVI-XIX. Escala 1:200.000. 1) Dominios del Pueblo de Tilcara; 2) Tierras compartidas por tilcaras y purmamarcas. Nota: La ubicación de pueblos y su dispersión es aproximada.

se presenta fuera de su órbita de poder y bajo la dirección de otro curaca: don Antonio Cama. Ahora la autoridad de Viltipoco y sus descendientes se extendió hacia el centro de la quebrada, sobre una serie de pueblos e indios innominados en los discursos.

¿Pero quiénes eran estos pueblos e indios de Viltipoco? ¿Cuándo y para qué echaron mano a los recursos mnemónicos de su sociedad?

"My Poderosso Señor Don Rodrigo de Yllescas Protector de los naturales en nombre de Don Felipe Viltipoco cassique prinsipal del pueblo de Tílcara repartimiento de Don Francisco de Argañarás en la Provinsia del Tucumán y de los demás yndios del dicho repartimiento, digo que a los sussodichos de tiempo ynmemorial aesta parte an tenido y posseydo e poseen al presente por tierras propias y por suyas la que estan desde la quebrada de Yucara hasta el río de Omaguaca y desde allí el río arriva hasta el asiento de Tumí de una banda y de otra y otras tierras en la que- brada de purmamarca hasta las tierras de Yucayra, y chelísto, y maymala y tilcara y tumí, en las quales ansido amparados por los mandamientos" [junio de 1606] (Sánchez 1996: 52 y 59). ${ }^{26}$

Primero, no nos sorprende el inmediato uso de la palabra escrita por parte de Felipe Viltipoco -intérprete y protector de naturales mediante- posible sucesor de don Diego. Asimismo, la contemporaneidad entre la pacificación de la quebrada (1595-1596) y el pedido de amparo al Rey es bastante clara de esta práctica (junio de 1606, corresponde a la fecha de comunicación de las autoridades locales españolas e indígenas del amparo real). Entonces, una primera incógnita se despeja: el pueblo de los Viltipoco se denominaba Tilcara.

Quisiéramos comentar el texto. El mismo se originó en un pleito por la intromisión de vecinos indígenas en 1699, en un potrero comprendido dentro de los límites del pueblo. Entonces los afectados para probar, confirmar y recordar sus derechos a un territorio presentan como prueba una cantidad de escritos provenientes de diferentes esferas de decisión de la burocracia administrativa colonial. Por lo tanto, nos enfrentamos a un texto que salta de una época a otra a medida que se insertan los papeles aprobatorios de una posesión: desde los títulos de propiedad otorgados por Felipe III en 1606, amparos ratificados por la Real Audiencia de La Plata y distintos gobernadores del Tucumán e, inclusive, un mandamiento de don Francisco de Alfaro, visitador de la gobernación.

Lo curioso es que el mismo se otorga por expreso pedido del cacique, según palabras del visitador, "y que aunque tenia mandamientos de amparo de los gobernadores de esta provinsia me pidieron les diese el mio pues era sin perjuicio de parte". La multiplicación de fechas y confirmaciones puede vincularse con la validez de la palabra escrita desde la perspectiva europea, ahora también nativa. Esta composición documental forjada en el procedimiento de unir diversos escritos, que a primera vista puede parecer incoherente y redundante en cuanto a fechas y personajes, deviene inteligible en la coherencia de la discursividad que enuncian. La posesión en el tiempo de un territorio circunscrito. Tal vez, la "incoherencia advertida" evidencia la "costumbre de colocar la memoria en un tiempo generacional más que general o

26 El destacado es nuestro. 
mundial". En el tiempo también se inscribe la memoria de la posesión, graficada en las frases "tiempo inmemorial, posesión siendo tan antigüa, posesión tan dilatada". La inmediata petición del curaca al rey refleja la memoria política de Tilcara y es lo que nos permite atribuirle raíces prehispánicas (Sánchez 2002 Ms).

La representación cartográfica reivindicada por el curaca puede ser percibida como un "mapa indígena" donde el líder étnico volcó la memoria histórica de un pueblo mediatizada por la posesión de un territorio. Este "mapa indígena" reúne un doble significado. El espacio como fundamento simbólico y ritual de una identidad, espacio emblemático de un encuentro entre ellos y sus dioses, tan antiguo que no hay memoria de cuándo empezó; circunscrito por un paisaje escrito a la manera de una toponimia, que no sólo confirma el mantenimiento de una tradición oral y simbólica, sino que actúa como puntos cardinales que definen y orientan el espacio terrestre: el territorio. Este plano geográfico-topográfico que describe las particularidades de su superficie se nos presenta bastante amplio y aglutina ecologías distintas y rutas de acceso a la puna y los valles. Además, cobijó un conjunto de población susceptible de ser fragmentada y organizada jerárquicamente, de acuerdo a la ecología o a las características de sus habitantes, como, por ejemplo, la cabecera de Tilcara y los asentamientos secundarios de Tumi y Maymala.

Parte de los topónimos se conservaron hasta la actualidad, los otros no figuran en cartografía alguna y tampoco aluden a un accidente geográfico específico.

Desde nuestra perspectiva y valoración, este acto comunicativo construye, recrea y transmite la memoria colectiva o social de una pertenencia a un espacio propio y prehispánico, ordenado de acuerdo a una alteridad política, económica y jerárquica. En este sentido, a la descripción ecológica podemos relacionarla con las culturas desprovistas de escritura, donde el espacio geográfico es un lugar común de memoria: cumbres, valles, quebradas y ríos, son posibles de ser leídos como señalizaciones y también como formas de relaciones con los antepasados. Invocada como una forma política de identidad, una defensa del territorio ante cualquier amenaza. Una reivindicación permanente del pasado, donde la memoria e historia estuvieron relacionadas a un territorio sagrado de origen.

Mediatizado por la documentación y su insalvable filtro español, hemos logrado percibir un "espacio, territorio y comunidad" como un pilar fundacional e inviolable de la memoria e identidad de Tilcara a través de los diferentes contextos históricos. Donde la eficaz acción de sus dirigentes étnicos y su "memoria noble" dejan apreciar la síntesis simbólica, religiosa, política y económica de los posibles, en ese territorio organizado. Posibles que se materializan a través de los vínculos con el mundo sobrenatural y en la práctica económica y social de las estrategias adoptadas para la vida cotidiana; un territorio étnico dinámico, patrimonio colectivo, que convive con una territorialidad administrativa y religiosa hispana, una memoria histórica activa que fue pasado, presente y futuro.

En el caso de Chile central en el "Pueblo de indios de Rapel" los indígenas tenían un acabado conocimiento de su espacio, y de los recursos y actividades que en él podían realizarse; dicho conocimiento se reforzaba con la conservación y transmisión de una memoria colectiva que circulaba de generación en generación entre los indígenas que se consideraban originarios de este pueblo.

Esto lo vemos en el deslinde de tierras pertenecientes a los indios del pueblo de Rapel realizado a inicios del siglo XVII, durante el cual los indígenas presentaron como testigos para señalar los límites de su espacio, anteriores a la reducción a "pueblo de indios", a los "yndios antiguos para que indicasen donde eran las dichas quebradas por ser los yndios naturales de la tiera [sic]". ${ }^{27}$ En la ocasión uno de ellos señaló que "todo lo qual saue como persona que a estado sienpre en Rapel y a caminado de hordinario este camino y conoçe muy bien los sitios dichos y nonbres dellos y de las quebradas y aberlo bisto y oydo" y por que "los antiguos en aquel tiempo [anterior] le llamauan asy". 28

27 Censos y capellanías, causa Rapel, 1630. Archivo de Santo Domingo, volumen 12, foja 10v. El destacado es nuestro.

28 Censos y capellanías, causa Rapel, 1630. Archivo de Santo Domingo, volumen 11, fojas $154 \mathrm{r}$ y $158 \mathrm{v}$. El destacado es nuestro. 
El hecho de que estos indígenas en el siglo XVII avalen sus declaraciones en el conocimiento que adquirieron de determinado espacio a través de los "antiguos" y de su propia experiencia, implica un entramado sutil de elementos, que fueron conformando la construcción de su espacio, y de las relaciones que dentro de éste se establecieron, tanto con la naturaleza como con los hombres. Además, este conocimiento fue transmitido y expresado entre los indígenas en su lengua, así como también las denominaciones que le daban a cada lugar, lo que nos permite plantear la existencia de una vitalidad y permanencia de una forma de aprehender el mundo, que coexiste entre, y a veces bajo, la "imagen de mundo" trazada e impuesta por el español en el Período Colonial.

En un sector de Chile central, denominado "pueblo de Cobquecura" en la documentación colonial (Figura 5), hacia 1695, los indios y el caci-

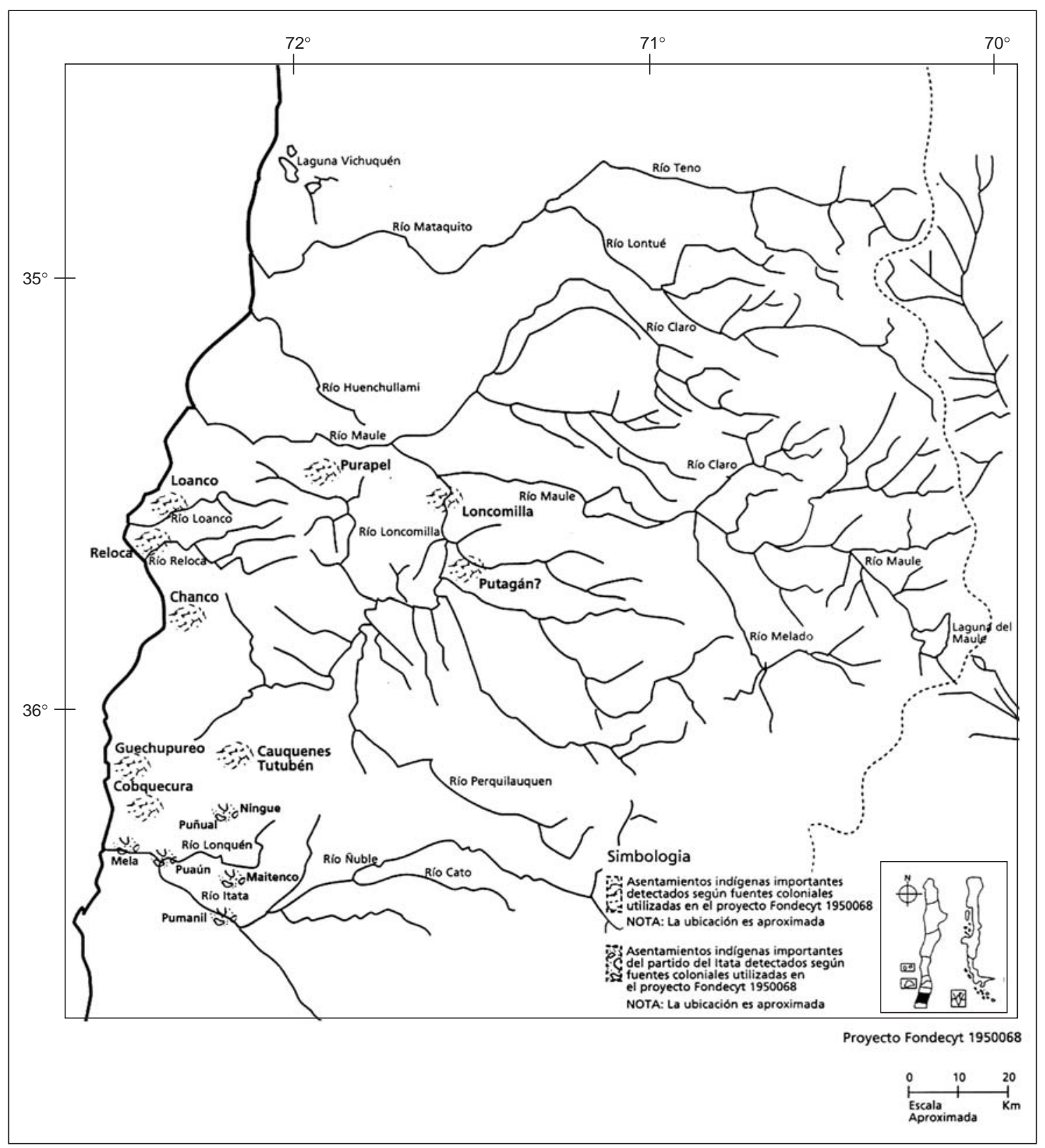

Figura 5. Entre los ríos Maule e Itata (siglos XVI-XVIII). 
que de este "pueblo", participaron en el deslinde y reconocimiento de las tierras que habían formado parte de sus espacios y territorios prereduccionales y fueron señalando las distintas "poblaciones de indios" que allí existieron, así como también los parajes, vegas, quebradas, valles, cursos de agua, que las componían. Lo interesante en términos de las relaciones trabajadas entre memoria, identidad y construcción de espacios es que los indios de Cobquecura señalaron como límite de sus tierras "la piedra nombrada Pilicura que está a las orillas del mar dentro de las tierras de dicho pueblo" 29 y junto a esto los testigos indios presentados declararon que "dixeron sauer de sierta siencia quales eran las tierras pertenesientes a dicho pueblo asi por auerlos vistos asimentados en ellos como por noticias de los antiguos". ${ }^{30}$ Es interesante señalar que estas tierras, hacia 1665, son indicadas por la administración hispana como "desiertas", lo que posibilita su ocupación por parte de los españoles para desarrollar en ellas la crianza de ganado o la agricultura, siendo los indígenas que las habitaban incorporados como mano de obra de los encomenderos y trasladados a otras estancias de la zona.

Percibimos a través de estos actos de la memoria mecanismos de construcción y reelaboración de una identidad, el de pertenecer a Cobquecura, relacionada con la utilización (productiva y ritual) de un espacio y un territorio que es considerado por los indígenas como propio. Además creemos que es significativo en la construcción de memoria y las identidades locales la existencia de topónimos de importancia asociados a elementos de la naturaleza que tienen un fuerte contenido simbólico y ritual para estas poblaciones; nos referimos a la existencia de la partícula "cura" 31 en el nombre de este lugar (Cobquecura) y en uno de sus límites (Pilicura), constantemente referido por los declarantes.

29 "Marcos de Alarcon con cacique de Cobquecura por tierras del pueblo." 1739]" en Archivo Nacional Fondo Real Audiencia, volumen 67 , foja 112 r. La referencia a estas antiguas poblaciones de indios de Cobquecura y a los recursos a los cuales ellos accedían también está en "Reduccion de los yndios de Coquecura [sic]" 1696]" en Archivo Nacional Fondo Real Audiencia, volumen 999, fojas 148r a 149v. El destacado es nuestro.

30 "Reducción..." en Archivo Nacional Fondo Real Audiencia volumen 999, foja 148r. El destacado es nuestro.

31 Piedra en mapudungun.

\section{Comentarios}

A partir de esta reflexión sobre los usos y formas de la memoria en diversos espacios coloniales y entre diversas poblaciones indígenas a través de la exploración de los "senderos de la memoria colectiva", surgen una serie de elementos que posibilitan complejizar el análisis y la mirada sobre estos espacios coloniales y quienes lo habitaron. Este es un estudio inicial y se abren una serie de nuevos temas y preguntas que esperamos abordar en futuras investigaciones.

Para las poblaciones indígenas el parentesco, los gentilicios y la apelación constante a los ancestros se constituyen como unas de las formas y usos fundamentales de la memoria colectiva indígena en estos tres espacios coloniales, permitiéndoles establecer un nexo de pertenencia entre el presente y un pasado previo a la conquista.

Con respecto a la relación que establecimos entre identidad y el uso cotidiano de la lengua "de la tierra" o "lengua por si" así como en su mantención y perpetuación a través de generaciones, se expresa una forma y un uso de la memoria. Junto a esto, percibimos que la apropiación del español por parte de los indígenas se convertirá en uso y otra forma de las memorias indígenas al dotar a esta lengua de nuevos contenidos.

A través de las "borracheras" como un beber social y comunitario, y la realización de juegos de chueca, los indígenas constituyeron espacios simbólicos y materiales de recuerdo y conexión con los ancestros, donde podían desplegar una serie de elementos que eran fundamento de identidad.

Como otras formas y usos de la memoria colectiva están las elaboraciones indígenas del tiempo, del espacio y de sus medidas, que no guardan relación con aquellas impuestas por los españoles, donde destaca el uso de herramientas mnemotécnicas como los quipus.

Finalmente, en las "memorias de la tierra" indagamos sobre la construcción de un espacio "indígena" de memoria colectiva como fundamento simbólico y ritual de una identidad, construido también como lugar de encuentro con sus deidades y sus ancestros; circunscrito por un paisaje escrito a la manera de una toponimia, que no sólo confirma la mantención de una tradición oral y simbólica, sino que actúa como puntos cardinales que definen y orientan el espacio terrestre: el territorio. 


\section{REFERENCIAS CITADAS}

ABERCROMBIE, T., 1998. Pathways of memory and power. University of Wisconsin, Madison, Wisconsin.

CASTRO, V., 1997. Huacca Muchay. Evangelización y religión andina en Charcas, Atacama La Baja. Tesis para optar al grado de Magíster en Historia, Mención Etnohistoria. Departamento de Ciencias Históricas, Facultad de Filosofía y Humanidades, Universidad de Chile, Santiago.

CASTRO, V. y J. L. MARTINEZ, 1996. Poblaciones indígenas de Atacama. En Culturas de Chile. Etnografía. Sociedades indígenas contemporáneas y su ideología, J. Hidalgo, V. Schiappacasse, H. Niemeyer, C. Aldunate y P. Mege (Eds.), pp. 69-110. Editorial Andrés Bello, Santiago.

CASTRO, N. y J. HIDALGO, 2001 [1999]. Brujos y brujería en la Atacama colonial. Inorganicidad de una representación ideológica y diseminación de una matriz cultural (Introducción y transcripción del "Cuadernos sobre barios delitos y supersticiones" del corregidor Manuel Fernández Valdivieso, Atacama s. XVIII). Estudios Atacameños 10: 91-124.

FOX, R., 1972. Sistemas de parentesco y matrimonio. Alianza Universidad, Alianza Editorial, Madrid.

GONGORA MARMOLEJO, A. de, 1990. Historia de todas las cosas que han acaecido en el Reino de Chile y de los que los han gobernado (1536-1575). Ediciones de la Universidad de Chile, Santiago.

HIDALGO, J., 1984. Descomposición cultural en Atacama en el siglo XVIII: Lengua, escuela, fugas y complementariedad ecológica. En Simposio Culturas Atacameñas. XLIV Congreso Internacional de Americanistas, pp. 221-249. Universidad del Norte, Antofagasta.

HIDALGO, J., N. HUME, M. MARSILLI y R. CORREA (Transcriptores), 1992. Padrón y Revisita de Atacama del Corregidor Alonso de Espejo, ordenada por el virrey Duque de La Palata. AGNA, sala IX 7:7:1, 52 fs. (Año 1683). Estudios Atacameños 10: 79-124.

LE GOFF, J., 1991. El orden de la memoria. El tiempo como imaginario. Ediciones Paidós Básica, Madrid.

MANRIQUEZ, V., 1997. Purum Aucca. Promaucaes de "no conquistados enemigos" a Indios en tierras de Puro, Rapel, Topocalma. Siglos XVI-XVIII. Tesis para optar al grado de Licenciada en Historia, Instituto de Historia, Pontificia Universidad Católica de Chile, Santiago.

2002 Ms. De Atacamas y atacameños. La construcción de identidades en Atacama colonial (siglos XVI Y XVII). En Informe Final Proyecto FONDECYT 1000148 "Historia Cultural y Materialidad en la Arqueología de los Periodos Intermedio Tardío y Tardío de San Pedro de Atacama y su Relación con la Cuenca del Río Loa".
MARTINEZ, J. L. (Transcriptor), 1992. España. Como vinieron de paz los yndios de Casabindo e se bautizaron el cacique su muger e hijos. AGI Patronato Legajo $188 \mathrm{~N}^{\circ} 1$, (Año 1557) 2 fs. Estudios Atacameños 10: 11.

1998. Pueblos del chañar y el algarrobo. Los atacamas en el siglo XVII. Ediciones de la Dirección de Bibliotecas, Archivos y Museos, Santiago.

OLIVARES, M. de, [s. XVIII] 1864. Historia militar, civil y sagrada de lo acaecido en la conquista y pacificación del reino de Chile, desde la primera entrada de los españoles, hasta la mitad del siglo décimo octavo de nuestra Redención. En Colección de Historiadores de Chile y de documentos relativos a la Historia Nacional, Colectados y publicados por José Toribio Medina, Tomo IV. Imprenta del Ferrocarril, Santiago.

- [s. XVIII] 1874. Historia de la Compañía de Jesús en Chile (1593-1736). En Colección de Historiadores de Chile y de documentos relativos a la Historia Nacional, Colectados y publicados por José Toribio Medina, tomo VII. Imprenta Andrés Bello, Santiago.

RICOEUR, P., 2003. La memoria, la historia, el olvido. Editorial Trotta, Madrid.

ROSALES, D. de, 1989. Historia general del reino de Chile, flandes indiano. Andrés Bello, Santiago.

SAIGNES, T. (Comp.), 1993. Borrachera y memoria. La experiencia de lo sagrado en los Andes. HISBOL/IFEA, La Paz.

SANCHEZ, S., 1996. Fragmentos de un tiempo largo. Tilcara entre fines del siglo XVI y principios del XIX. Tesis de Licenciatura, Universidad Nacional de Jujuy, San Salvador de Jujuy.

_-2001 Ms. Discursos y alteridades en la quebrada de Humahuaca: Parentesco, identidad, territorio y memoria.

2002 Ms. De "Tilcaras Ticas" a comunidad. Los indios del Pueblo de Tilcara. Jujuy-Argentina. Siglos XVI-XIX.

VIVAR, G. de, [1558] 1979. Crónica y relación copiosa y verdadera de los Reinos de Chile, Ed. Leopoldo Sáez G., Bibliotheca Ibero-Americana, Colloquium Verlag, Berlín.

\section{Documentos}

Archivo de Santo Domingo

Censos y capellanías, causa Rapel, 1630, volumen 11.

Censos y capellanías, causa Rapel, 1630, volumen 12.

Archivo Nacional

Marcos de Alarcon con cacique de Cobquecura por tierras del pueblo. [1739]. Fondo Real Audiencia volumen 67. 
Colegio de San Sebastián de Bucalemu con el capitán Juan de Ureta sobre restitución de indios de Melipilla reducidos en Bucalemu, 1660-1666. Fondo Real Audiencia volumen 673 .

"Reduccion de los yndios de Coquecura" [1696]". Fondo Real Audiencia volumen 999.

Haciendas de Peteroa y Villavicencio de los herederos del general Luis Jufré. Causa entre Martín de Briones y Pedro Fonseca sobre cuentas de la administración de las haciendas de Luis Jufré en Peteroa y sus términos. 1618. Fondo Real Audiencia volumen 1065 pieza 1.
"Litigio por el cacicazgo del pueblo de indios de Guenchullami”, s/f, siglo XVIII”. Fondo Real Audiencia volumen 1160 pieza 3 .

Visita al obraje de Peteroa del capitán Juan Jufré, realizada por el visitador general capitán Gregorio Sánchez, 16021609”. Fondo Real Audiencia volumen 1700.

"Autos fechos sobre la vacante de la encomienda de yndios del pueblo de Cauquenes ... [1679]". Fondo Real Audiencia volumen 2750 . 